Research Article

\title{
Effect of Basalt Fiber on Static and Dynamic Mechanical Properties of Metakaolin-Based Cement Clay
}

\author{
Kun Huang, ${ }^{1,2}$ Qinyong $M a \mathbb{D}^{1,2}$ and Dongdong $\mathrm{Ma}^{1,2}$ \\ ${ }^{1}$ Research Center of Mine Underground Engineering, Ministry of Education, Beijing, China \\ ${ }^{2}$ Anhui University of Science and Technology, Huainan, Anhui 232001, China \\ Correspondence should be addressed to Qinyong Ma; qymaah@126.com
}

Received 3 January 2020; Revised 21 September 2020; Accepted 24 September 2020; Published 21 October 2020

Academic Editor: Melina Bosco

Copyright (c) 2020 Kun Huang et al. This is an open access article distributed under the Creative Commons Attribution License, which permits unrestricted use, distribution, and reproduction in any medium, provided the original work is properly cited.

To investigate the effects of basalt fiber content on the mechanical properties and microstructure characteristic of metakaolinbased cement clay, the static and dynamic uniaxial compressive and splitting tensile, nuclear magnetic resonance (NMR), and scanning electron microscope (SEM) tests were performed to study the stress-strain curves, static and dynamic peak stress, pore distribution characteristic, and reinforcement mechanism. In this research, the basalt fiber with the length of $12 \mathrm{~mm}$ were selected and the ratios between fiber and dry soil were $0 \%, 0.5 \%, 1.0 \%, 1.5 \%$, and $2.0 \%$, respectively. The obtained results showed a noticeable difference of stress-strain curve characteristics in the static and dynamic compressive tests. A positive correlation between deformation modulus and compressive strength was found for both static and dynamic tests. The addition of basalt fiber could efficiently increase the static and dynamic strengths of metakaolin-based cement clay, and the increment $66.15 \%$ and $74.63 \%$ was observed at $1.0 \%$ basalt fiber content for static and dynamic compressive strengths, respectively, while the corresponding increment values were $93.75 \%$ and $97.62 \%$ for its splitting tensile strengths, respectively. The basalt fiber could decrease the porosity of cement clay; moreover, the reinforcement mechanism of metakaolin and basalt fiber to cement clay was analyzed based on the SEM test results.

\section{Introduction}

Fiber reinforced cement soil was a reinforced composite material with high strength and plastic deformation capacity and had been widely used in construction engineering [1-3]. Previous investigation results showed that the mechanical properties of cement soil could be effectively enhanced by adding an appropriate amount of fiber [4-6]. Currently, fibers used in engineering can be divided into two categories: natural fibers and synthetic fibers. Tran et al. [7] explored the effect of cornsilk fiber on mechanical properties of cement soil, and the experimental results revealed that the addition of cornsilk fiber improved both the compressive and splitting tensile strengths of cement soil specimens. Natural fibers had high availability and were relatively cheap, while it showed weak working performance. Therefore, the exploration of environmental-friendly high-performance fiber was necessary and urgent [8]. The raw material of basalt fiber was natural volcanic rock, and it did not produce toxic substances and industry waste during production process. Moreover, basalt fiber was a typical silicate fiber, which had good compatibility with cement-based materials [9]. Chen [10] found that the tensile strength and plastic deformation capacity could be improved by mixing appropriate content of basalt fiber. In addition, compared with the unreinforced specimen, the freeze-thaw resistance of basalt fiber reinforced specimen had a notable increase $[11,12]$. However, the production process of cement consumed a lot of energy and produced high carbon emission, which contributed to global warming and climate change [13]. As an environmental-friendly material, the mechanical properties and the durability of cement soil could be enhanced by metakaolin, which would promote the hydration reaction of cement and produce more hydration products $[14,15]$. With laboratory and field tests, metakaolin could significantly inhibit the moisture sensitivity of cement soil, which is beneficial to 
roller compaction tests at the site and showed high practicality and economy $[16,17]$.

By summarizing the existing literature, it could be noticed that numerous studies had been devoted on the static mechanical properties of fiber reinforced cement soil. However, many engineering practices, such as impact of airplane landing on the airport subgrade, rapid load testing piles, and evaluation of soil stability under earthquake load, involving cement soil responded dynamic loads [18]. Hence, it was meaningful to research the influence of basalt fiber content on dynamic mechanical properties of cement soil. Santoni and Webster [19] used polypropylene fiber to improve the bearing capacity of the subgrade, which could meet the requirement of large transport aircraft. Ma and Gao [20] carried out a series of dynamic compressive and tensile tests on cement soil with various basalt fiber contents. The test results showed that energy absorption firstly increased and then decreased with the inclusion of basalt fiber, and the energy absorption capacity was unresponsive to an increase of basalt fiber content when the basalt fiber content was more than the optimum content due to the existence of weak surface made by excess basalt fiber.

The objective of this study was to study the effect of basalt fiber content on the static and dynamic behavior of metakaolincement soil. A series of tests were carried out with various basalt fiber contents and strain rates with the help of WDW-20 microcomputer-controlled electronic and Split Hopkinson pressure bar (SHPB) devices. The effects of fiber content on static and dynamic strengths and deformation modulus $\left(E_{50}\right)$ were studied. Microscopic testing methods were adopted to research the variation in the microscopic structure of internal pores and reveal the fiber reinforcement mechanism.

\section{Materials and Test Methods}

2.1. Test Design. To investigate the effect of fiber content on strength and deformation properties of metakaolin-cement soil, the static and dynamic uniaxial compressive and splitting tensile were employed in this experiment. 15\% binder (mass ratio of binder to dry soil) was adopted to stabilize the clay according to the design guidelines for cemented soil pile established by standard JGJ 79-2012 [21]. The test design was displayed in Table 1.

2.2. Materials. Stabilization materials used in this study include dry clay, cement, metakaolin, basalt fiber, and water.

2.2.1. Clay. The clay was derived from a foundation pit in Huainan, and the sample was collected in a disturbed state. The clay was taken from a horizon of $3 \mathrm{~m}$ thickness approximately to get rid of the organic soil layer. The soil parameters and particle size distribution were listed in Tables 2 and 3, respectively.

2.2.2. Cement. Ordinary Portland cement (P.O 42.5) was used in the work which was provided by the Huainan Bagongshan cement factory and the characteristic parameters were listed in Table 4. The content of cement was $13 \%$ by the weight of dry soil.

2.2.3. Metakaolin. The metakaolin was produced by the Hunan Chaopai company and its characteristic parameters were illustrated in Table 5. The fineness was 1250 meshes and the activity index was more than 110 . The content of metakaolin was $2 \%$ by the weight of dry soil.

2.2.4. Basalt Fiber. The basalt fiber used in this study was industrial products from Haining Company in Ningbo, Zhejiang province, and its performance index was listed in Table 6. Chopped basalt fibers were $12 \mathrm{~mm}$ in length, and the content used in the study was $0 \%, 0.5 \%, 1 \%, 1.5 \%$, and $2 \%$ by the weight of dry soil, respectively, as seen in Figure 1.

2.2.5. Water. Distilled water from a laboratory was used for specimen preparation.

2.3. Specimen Preparation. The fiber reinforced and unreinforced specimens used in the study were prepared by mixing dry clay, cement, metakaolin, basalt fiber, and water. Following the Chinese Standard for the geotechnical testing method (GB/T 50123-2019) [22], the clay was dried, crushed, and passed through a $2 \mathrm{~mm}$ sieve. First, dry clay and basalt fiber was mixed homogeneously by hand. Then, distilled water was added into the mixture and uniformly mixed based on the initial moisture content of the specimen. After that, the mixture was stored in a closed bag for more than $24 \mathrm{~h}$ to provide soil particles with adequate time to completely absorb the water. Finally, add metakaolin, cement, and water (the water-cement ratio is 0.5 ). During the mixing process, it is necessary to add the fibers before adding the water. This method can effectively reduce the phenomenon of fibers being tangled. Visual and microscope examination of specimens showed the mixtures to be satisfactorily uniform.

The mixture was statically compacted at least three layers inside a specific mold which was lubricated. The top of each layer was slightly scarified. After the compacting process, the specimen was extracted from the mold, covered by plastic bags to avoid significant variations of moisture content, and then kept in the laboratory for 28 days before subjecting to experiment tests.

2.4. Static Compressive Test and Split Tensile Test. WDW-20 microcomputer-controlled electronic universal testing machine with a maximum load sensor of $20 \mathrm{kN}$ and resolutions of $5 \mathrm{~N}$ was used for both static compressive and split tensile tests. The displacement rate adopted $1 \mathrm{~mm} / \mathrm{min}$. The loading mode and the geometry size of the specimen of static compressive and split tensile tests were illustrated in Figures 2 and 3, respectively.

Before subjecting these tests, the bearing surface of specimen was polished to achieve a smooth surface, which can ensure that the surface of testing specimens were 
TABle 1: Test design.

\begin{tabular}{lcccc}
\hline Test types & Specimen size $(\mathrm{mm})$ & Specimen amount & Cement & $\begin{array}{c}\text { Material usage (\%) } \\
\text { Metakaolin }\end{array}$ \\
\hline Static compressive test & $70.7 \times 70.7 \times 70.7$ & 3 & & \\
Split tensile test & $\Phi 50 \times H 50$ & 3 & 13 & 2 \\
Dynamic compressive test & $\Phi 50 \times H 25$ & 5 & & $0,0.5,1,1.5,2$ \\
Dynamic tensile test & $\Phi 50 \times H 25$ & 5 & \\
\hline
\end{tabular}

Note. $\Phi$ and $H$ were the diameter and the height of specimen, respectively.

TABLE 2: Soil parameters.

\begin{tabular}{lcccc}
\hline Soil type & Initial moisture content (\%) & Liquid limit (\%) & Plastic limit (\%) & Plasticity index \\
\hline Clay & 23.1 & 43 & 21 & 22 \\
\hline
\end{tabular}

TABle 3: Particle size distribution.

\begin{tabular}{|c|c|c|c|c|c|}
\hline Particle size $(\mathrm{mm})$ & $0 \sim 0.1$ & $0.1 \sim 0.25$ & $0.25 \sim 0.5$ & $0.5 \sim 1.0$ & $1.0 \sim 2.0$ \\
\hline Percentage (\%) & 18.68 & 11.00 & 14.62 & 34.40 & 21.30 \\
\hline
\end{tabular}

TABLE 4: The characteristic parameters of cement.

\begin{tabular}{lcccccccc}
\hline Composition & $\mathrm{SiO}_{2}$ & $\mathrm{Al}_{2} \mathrm{O}_{3}$ & $\mathrm{CaO}$ & $\mathrm{Fe}_{2} \mathrm{O}_{3}$ & $\mathrm{SO}_{3}$ & $\mathrm{MgO}$ & $\mathrm{Na}_{2} \mathrm{O}$ & $\mathrm{K}_{2} \mathrm{O}$ \\
\hline Percentage (\%) & 19.6 & 6.5 & 66.3 & 3.5 & 2.5 & 0.7 & 0.6 & 0.3 \\
\hline
\end{tabular}

TABLE 5: The characteristic parameters of metakaolin.

\begin{tabular}{lcccccc}
\hline Composition & $\mathrm{SiO}_{2}$ & $\mathrm{Al}_{2} \mathrm{O}_{3}$ & $\mathrm{Fe}_{2} \mathrm{O}_{3}$ & $\mathrm{Na}_{2} \mathrm{O}$ & $\mathrm{K}_{2} \mathrm{O}$ & Others \\
\hline Percentage (\%) & 54 & 43 & 1 & 0.3 & 0.2 & 1.5 \\
\hline
\end{tabular}

TABle 6: Performance index of basalt fiber.

\begin{tabular}{lccccc}
\hline Length $(\mathrm{mm})$ & Filament diameter $(\mu \mathrm{m})$ & Density $\left(\mathrm{g} \cdot \mathrm{cm}^{-3}\right)$ & Elastic modulus $(\mathrm{GPa})$ & Tensile strength $(\mathrm{MPa})$ & Fracture elongation $(\%)$ \\
\hline 12 & $7-15$ & $2.63-2.65$ & $95 \sim 115$ & $3300 \sim 4500$ & $2.4 \sim 3.0$ \\
\hline
\end{tabular}

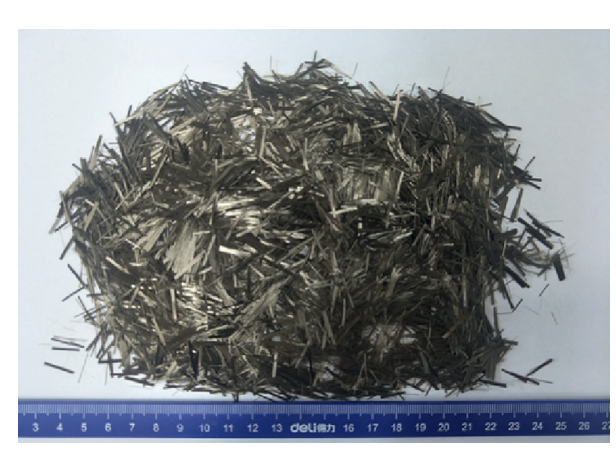

Figure 1: Basalt fiber.

perpendicular to the applied axial load. Then, the size and mass of specimen were recorded and the results were illustrated in Table 7. The Vaseline was applied on the top and bottom faces of samples, which could effectively reduce the friction between the specimen and loading plate.

2.5. Dynamic Compressive Test and Dynamic Tensile Test. SHPB with $50 \mathrm{~mm}$ diameter was adopted, as illustrated in Figure 4. It contained an inflating device, a strike bar, a laser velocimeter, an incident bar, a transmitter bar, and an absorbing bar. The data acquisition system consisted of two parts, namely, a super dynamic strain instrument and an oscilloscope. The lengths of incident, transmitter, and absorbing bars were $2000 \mathrm{~mm}, 1500 \mathrm{~mm}$, and $500 \mathrm{~mm}$, respectively. The length of the strike bar was $350 \mathrm{~mm}$, and its material and maximum diameter were the same with those of the abovementioned bars. To acquire the typical failure mode, the impact pressure of dynamic compressive test and dynamic tensile test was $0.5 \mathrm{MPa}$ and $0.3 \mathrm{MPa}$, respectively [15]. 


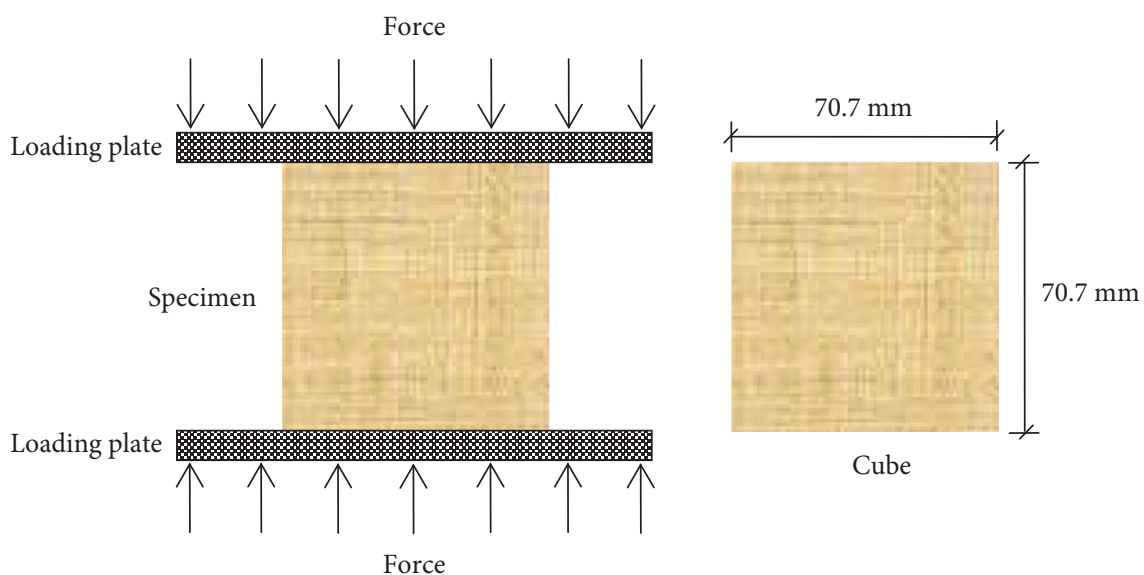

FIGURE 2: Static compressive test.

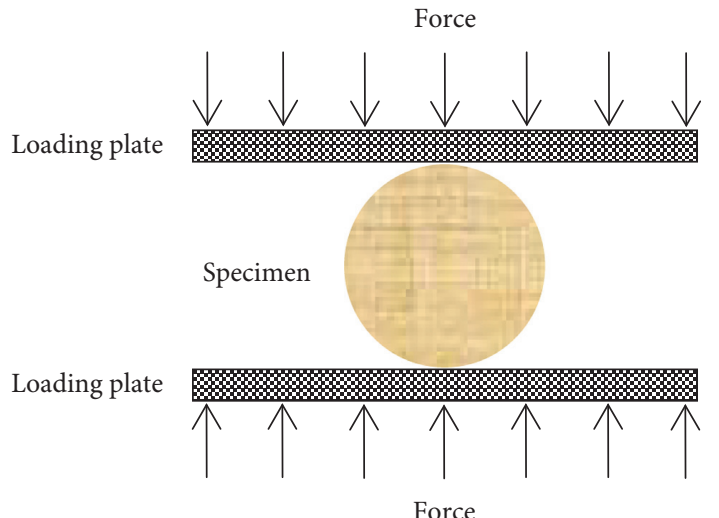

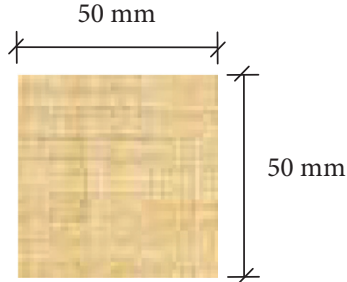

Cylinder

Figure 3: Static split tensile test.

Before the SHPB test, the surfaces of incident, transmitter, and striker bars were cleaned with alcohol, and a thin layer of Vaseline was smeared on the surface of the specimen. Strain gauge and semiconductor strain gauge were mounted on the surface of incident bar and transmitter bar, respectively. A laser velocipede was prepared to measure the velocity of the striker. A gas gun was filled with nitrogen to expected pressure for launching the striker. An incident wave was transmitted from the incident bar to the specimen when the striker impacts the incident bar, and the strain gauge would collect the incident wave single. The reflection and transmission phenomenon was generated on the interface between the specimen and bars because of the wave impedance difference between cement clay specimen and bars. The stress equilibrium state could reach after the repeated transmission and reflection of stress in the sample. The reflect waves and transmitted waves would be recorded by the strain gauge and the semiconductor strain gauge, respectively. The computerized data acquisition system continuously recorded the three-wave signals generated during impact. Based on elastic stress wave theory and uniform stress assumption, the dynamic compressive strength $\left(\sigma_{\mathrm{s}}\right)$ and dynamic tensile strength $\left(\sigma_{\mathrm{t}}\right)$ could be calculated $[23,24]$ as follows:

$$
\left.\begin{array}{l}
\sigma_{\mathrm{s}}(t)=\frac{E_{\mathrm{e}} A_{\mathrm{e}}}{2 A_{\mathrm{s}}}\left[\varepsilon_{\mathrm{I}}(t)++\varepsilon_{\mathrm{R}}(t)+\varepsilon_{\mathrm{T}}(t)\right] \\
\varepsilon_{\mathrm{s}}(t)=\frac{C_{\mathrm{e}}}{L_{\mathrm{s}}} \int_{o}^{\tau}\left[\varepsilon_{\mathrm{I}}(t)-\varepsilon_{\mathrm{R}}(t)-\varepsilon_{\mathrm{T}}(t)\right] d_{\mathrm{t}} \\
\dot{\varepsilon}_{\mathrm{s}}(t)=\frac{C_{e}}{L_{\mathrm{s}}}\left[\varepsilon_{\mathrm{I}}(t)-\varepsilon_{\mathrm{R}}(t)-\varepsilon_{\mathrm{T}}(t)\right] \\
\sigma_{\mathrm{t}}(t)=\frac{E_{\mathrm{e}} A_{\mathrm{e}}}{2 \pi D L_{\mathrm{s}}}\left[\varepsilon_{\mathrm{I}}(t)+\varepsilon_{\mathrm{R}}(t)+\varepsilon_{\mathrm{T}}(t)\right] \\
\varepsilon_{\mathrm{t}}(t)=\frac{C_{\mathrm{e}}}{D} \int_{o}^{\tau}\left[\varepsilon_{\mathrm{I}}(t)-\varepsilon_{\mathrm{R}}(t)-\varepsilon_{\mathrm{T}}(t)\right] d_{\mathrm{t}} \\
\dot{\varepsilon}_{\mathrm{t}}(t)=\frac{C_{\mathrm{e}}}{D}\left[\varepsilon_{\mathrm{I}}(t)-\varepsilon_{\mathrm{R}}(t)-\varepsilon_{\mathrm{T}}(t)\right]
\end{array}\right\},
$$

where $\varepsilon_{I}(t), \varepsilon_{R}(t)$, and $\varepsilon_{T}(t)$ were the incident, reflected, and transmitted waves, respectively; $E_{\mathrm{e}}, A_{\mathrm{e}}$, and $C_{\mathrm{e}}$ were Young's modulus $(\mathrm{MPa})$, cross-sectional area $\left(\mathrm{mm}^{2}\right)$, and elastic wave speed $(\mathrm{m} / \mathrm{s})$ of the bar, respectively; $A_{\mathrm{s}}, L_{\mathrm{s}}$, and $D$ were 
TABLE 7: Physical parameters of specimens.

\begin{tabular}{|c|c|c|c|}
\hline Sample number & Sample size $(\mathrm{mm})$ & Mass (g) & Density $\left(\mathrm{g} \cdot \mathrm{mm}^{-3} \times 10^{-3}\right)$ \\
\hline \multicolumn{4}{|c|}{ Static compressive test } \\
\hline $28 \mathrm{~d}-0 \%-1$ & $70.56 \times 70.83 \times 70.49$ & 675.16 & 1.91 \\
\hline $28 \mathrm{~d}-0 \%-2$ & $70.58 \times 71.18 \times 70.56$ & 667.38 & 1.88 \\
\hline $28 \mathrm{~d}-0 \%-3$ & $70.08 \times 70.71 \times 70.79$ & 670.96 & 1.91 \\
\hline $28 \mathrm{~d}-0.5 \%-1$ & $70.65 \times 70.51 \times 70.86$ & 663.16 & 1.88 \\
\hline $28 \mathrm{~d}-0.5 \%-2$ & $70.56 \times 70.55 \times 70.66$ & 662.51 & 1.88 \\
\hline $28 \mathrm{~d}-0.5 \%-3$ & $70.94 \times 70.66 \times 70.54$ & 667.57 & 1.88 \\
\hline $28 \mathrm{~d}-1 \%-1$ & $70.58 \times 70.95 \times 71.18$ & 672.69 & 1.89 \\
\hline $28 \mathrm{~d}-1 \%-2$ & $70.37 \times 71.81 \times 70.39$ & 662.72 & 1.86 \\
\hline $28 \mathrm{~d}-1 \%-3$ & $70.76 \times 71.40 \times 70.44$ & 668.67 & 1.88 \\
\hline $28 \mathrm{~d}-1.5 \%-1$ & $70.89 \times 70.92 \times 70.46$ & 665.63 & 1.88 \\
\hline $28 \mathrm{~d}-1.5 \%-2$ & $70.72 \times 70.86 \times 70.54$ & 669.08 & 1.89 \\
\hline $28 \mathrm{~d}-1.5 \%-3$ & $70.88 \times 70.93 \times 71.08$ & 668.31 & 1.87 \\
\hline $28 \mathrm{~d}-2 \%-1$ & $70.81 \times 70.66 \times 70.06$ & 666.89 & 1.90 \\
\hline $28 \mathrm{~d}-2 \%-2$ & $70.74 \times 71.01 \times 70.09$ & 673.21 & 1.91 \\
\hline $28 \mathrm{~d}-2 \%-3$ & $70.84 \times 71.18 \times 70.34$ & 668.69 & 1.89 \\
\hline \multicolumn{4}{|c|}{ Dynamic compressive test } \\
\hline $28 \mathrm{~d}-0 \%-4$ & $50.27 \times 24.79$ & 95.44 & 1.94 \\
\hline $28 \mathrm{~d}-0 \%-5$ & $50.20 \times 24.79$ & 92.78 & 1.89 \\
\hline $28 d-0 \%-6$ & $49.61 \times 24.94$ & 95.28 & 1.97 \\
\hline $28 \mathrm{~d}-0.5 \%-4$ & $50.24 \times 25.05$ & 95.46 & 1.92 \\
\hline $28 \mathrm{~d}-0.5 \%-5$ & $50.27 \times 24.78$ & 93.62 & 1.90 \\
\hline $28 d-0.5 \%-6$ & $49.65 \times 24.75$ & 92.28 & 1.93 \\
\hline $28 \mathrm{~d}-1 \%-4$ & $50.52 \times 24.70$ & 93.89 & 1.90 \\
\hline $28 \mathrm{~d}-1 \%-5$ & $50.49 \times 24.61$ & 93.98 & 1.91 \\
\hline $28 \mathrm{~d}-1 \%-6$ & $49.94 \times 24.55$ & 93.35 & 1.94 \\
\hline $28 \mathrm{~d}-1.5 \%-4$ & $49.71 \times 24.92$ & 93.84 & 1.94 \\
\hline $28 \mathrm{~d}-1.5 \%-5$ & $50.32 \times 24.66$ & 92.89 & 1.89 \\
\hline $28 \mathrm{~d}-1.5 \%-6$ & $50.38 \times 24.49$ & 94.63 & 1.93 \\
\hline $28 \mathrm{~d}-2 \%-4$ & $50.30 \times 24.83$ & 94.15 & 1.91 \\
\hline $28 d-2 \%-5$ & $50.17 \times 24.75$ & 94.02 & 1.92 \\
\hline $28 \mathrm{~d}-2 \%-6$ & $50.61 \times 24.78$ & 94.13 & 1.89 \\
\hline \multicolumn{4}{|l|}{ Split tensile test } \\
\hline $28 \mathrm{~d}-0 \%-1$ & $50.44 \times 50.04$ & 190.73 & 1.91 \\
\hline $28 \mathrm{~d}-0 \%-2$ & $50.42 \times 50.15$ & 189.94 & 1.90 \\
\hline $28 d-0 \%-3$ & $50.23 \times 49.89$ & 186.88 & 1.89 \\
\hline $28 \mathrm{~d}-0.5 \%-1$ & $50.69 \times 50.15$ & 178.58 & 1.77 \\
\hline $28 \mathrm{~d}-0.5 \%-2$ & $50.33 \times 49.85$ & 187.00 & 1.89 \\
\hline $28 \mathrm{~d}-0.5 \%-3$ & $50.48 \times 50.05$ & 188.62 & 1.88 \\
\hline $28 \mathrm{~d}-1 \%-1$ & $50.64 \times 49.91$ & 189.33 & 1.88 \\
\hline $28 \mathrm{~d}-1 \%-2$ & $50.63 \times 49.95$ & 190.89 & 1.89 \\
\hline $28 \mathrm{~d}-1 \%-3$ & $50.40 \times 49.66$ & 185.91 & 1.87 \\
\hline $28 \mathrm{~d}-1.5 \%-1$ & $50.96 \times 49.89$ & 187.56 & 1.84 \\
\hline $28 \mathrm{~d}-1.5 \%-2$ & $50.53 \times 49.85$ & 188.21 & 1.88 \\
\hline $28 \mathrm{~d}-1.5 \%-3$ & $50.62 \times 49.90$ & 185.67 & 1.85 \\
\hline $28 \mathrm{~d}-2 \%-1$ & $50.39 \times 49.98$ & 186.29 & 1.87 \\
\hline $28 d-2 \%-2$ & $50.49 \times 49.92$ & 186.58 & 1.87 \\
\hline $28 \mathrm{~d}-2 \%-3$ & $50.66 \times 50.26$ & 188.03 & 1.86 \\
\hline \multicolumn{4}{|c|}{ Dynamic tensile test } \\
\hline $28 \mathrm{~d}-0 \%-4$ & $49.55 \times 25.27$ & 93.35 & 1.92 \\
\hline $28 d-0 \%-5$ & $50.21 \times 25.31$ & 93.32 & 1.86 \\
\hline $28 \mathrm{~d}-0 \%-6$ & $50.72 \times 24.50$ & 95.81 & 1.94 \\
\hline $28 \mathrm{~d}-0.5 \%-4$ & $50.27 \times 25.19$ & 96.60 & 1.93 \\
\hline $28 \mathrm{~d}-0.5 \%-5$ & $50.22 \times 24.67$ & 94.48 & 1.93 \\
\hline $28 \mathrm{~d}-0.5 \%-6$ & $50.42 \times 24.65$ & 95.27 & 1.94 \\
\hline $28 \mathrm{~d}-1 \%-4$ & $50.26 \times 24.57$ & 94.48 & 1.94 \\
\hline $28 \mathrm{~d}-1 \%-5$ & $50.44 \times 24.91$ & 93.81 & 1.89 \\
\hline $28 \mathrm{~d}-1 \%-6$ & $50.47 \times 24.73$ & 95.36 & 1.93 \\
\hline $28 \mathrm{~d}-1.5 \%-4$ & $50.80 \times 24.74$ & 93.98 & 1.88 \\
\hline $28 \mathrm{~d}-1.5 \%-5$ & $50.26 \times 24.51$ & 93.46 & 1.92 \\
\hline $28 \mathrm{~d}-1.5 \%-6$ & $50.37 \times 24.81$ & 95.13 & 1.93 \\
\hline $28 \mathrm{~d}-2 \%-4$ & $50.30 \times 25.25$ & 96.21 & 1.92 \\
\hline $28 d-2 \%-5$ & $50.36 \times 24.61$ & 93.07 & 1.90 \\
\hline $28 d-2 \%-6$ & $50.43 \times 24.62$ & 93.82 & 1.91 \\
\hline
\end{tabular}




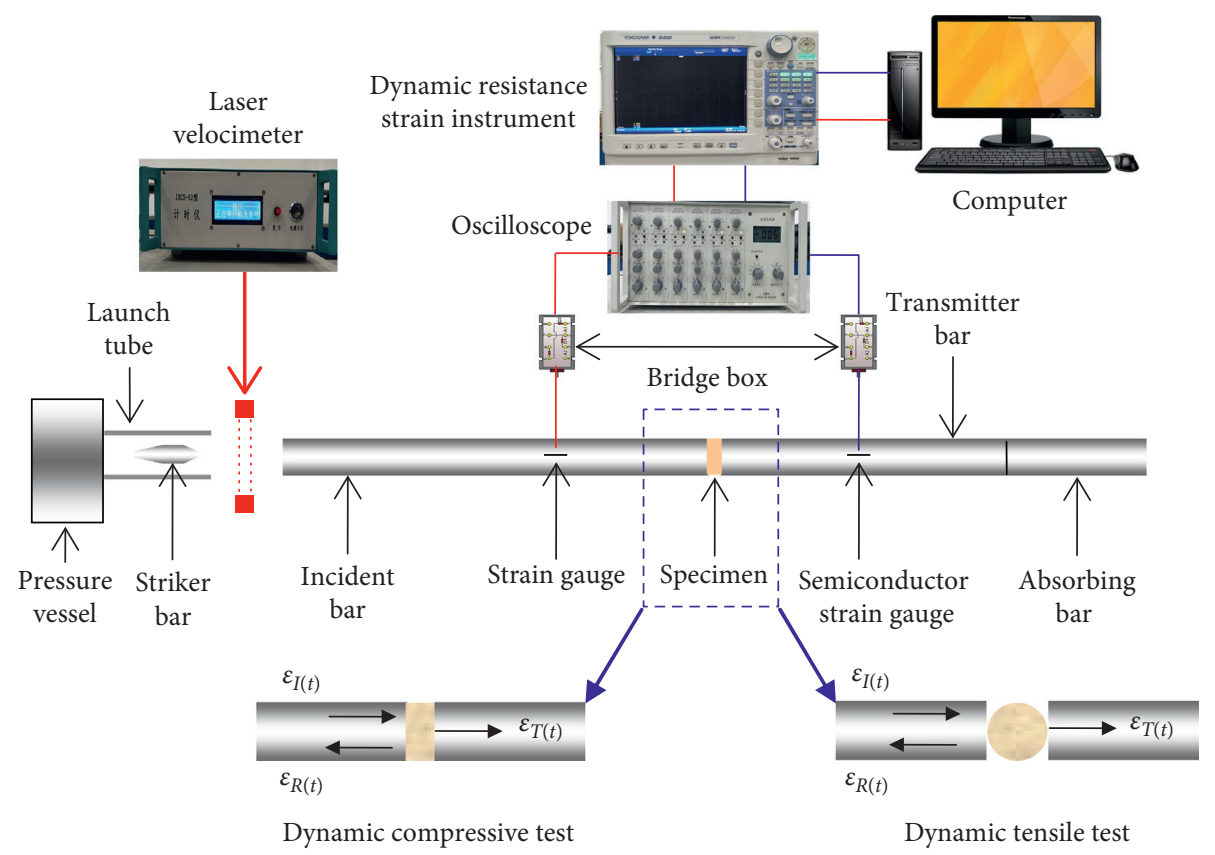

Figure 4: Schematic diagram of the SHPB system testing device.

the cross-sectional area $\left(\mathrm{mm}^{2}\right)$, height $(\mathrm{mm})$, and diameter ( $\mathrm{mm}$ ) of the cement clay specimen, respectively; and $\tau$ was the duration time $(\mu s)$ of elastic wave.

\section{Test Results}

3.1. Stress-Strain Curve. The strength and deformation characteristics of the specimen could be reflected by the stress-strain curve. Based on the test data, the typical stress-strain curve of cement clay under static compressive test was illustrated in Figure 5(a), and it could be divided into four stages: consolidation stage (O-A), linear elastic stage (A-B), plastic deformation stage (B-C), and failure stage $(C-D)$. During the consolidation stage, the internal pores were closed, and the strain and elasticity modulus was growing fast. Then, going to the linear elastic stage, the stress was approximately linearly increasing with the variety of strain. In the plastic deformation stage, the internal pores and cracks would accelerate expansion under high pressure. Hence, the growth rate of stress showed a downtrend before reaching peak stress. In the failure stage, the bearing capacity of specimens was obvious to decrease. As a contrast, the curves under the dynamic compressive test (shown in Figure 5(b)) contained three stages: approximate elastic deformation $\left(\mathrm{O}_{1^{-}}\right.$ $\left.A_{1}\right)$, plastic deformation $\left(A_{1}-B_{1}\right)$, and failure stage $\left(B_{1^{-}}\right.$ $\mathrm{C}_{1}$ ). The duration time of dynamic loading was shorter than static loading. The internal cracks had insufficient time to extend and propagate, and some main cracks developed rapidly. Hence, the consolidation stage of dynamic tests was not obvious [15].

As the anisotropy, nonhomogeneity, and elastoplasticity material, cement clay contained numerous internal pores and cracks. Hence, the relationships between stress and strain showed nonlinear characteristics, as illustrated in Figure 6.
When fiber content increased from $0 \%$ to $1 \%$, the compressive strength and the slope of the stress-strain curve with fiber were higher than that of the unreinforced specimen. The above experimental results indicated that the ability of resist deformation was improved by mixing fibers. With the further increase of fiber content $(1 \% \sim 2 \%)$, the compressive strength showed a downtrend, while it was still higher than that of fiber unreinforced cement soil. Hence, the fiber content should be controlled within a reasonable range.

$E_{50}$ was an important parameter in the foundation supporting design and ground treatment [25]. The definition of $E_{50}$ was equal to the slope of the line from the origin point to the point corresponded to $50 \%$ peak stress on the stress-strain curve. The value of $E_{50}$ should be 80 to 120 times higher than the static compressive strength for cement-treated soil by JGJ79-2012 [21]. However, these factors, such as soil type, cement type, fibers content, and curing environment, had a notable effect on the ratio between $E_{50}$ and compressive strength. Hence, the relationship between $E_{50}$ and static compressive strength showed an obvious difference in previous literature. Du et al. [26] investigated cement-treated zinc-contaminated soil and found that the ratios between $E_{50}$ and compressive ranged from 18 to 53. Wang et al. [27] reported that the ratio between $E_{50}$ and compressive ranged from 51 to 80 for sandy soil. The $E_{50}$ and peak stress of Belite cement and Ordinary Portland cement-treated clay were researched, and the ratio was 79 and 107, respectively [28]. In this study, the ratio between $E_{50}$ and static compressive strength ranged from 53 to 95, as shown in Figure 7, while the ratio ranged from 59 to 232 under dynamic loading. It could be seen that the $E_{50}$ and compressive strength under dynamic load were higher than those under the static compressive test, and the deformation modulus increased with the increase of peak stress. 


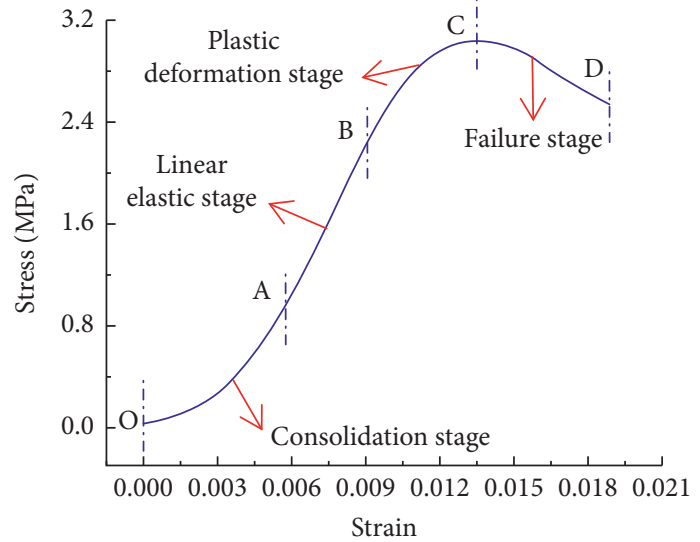

(a)

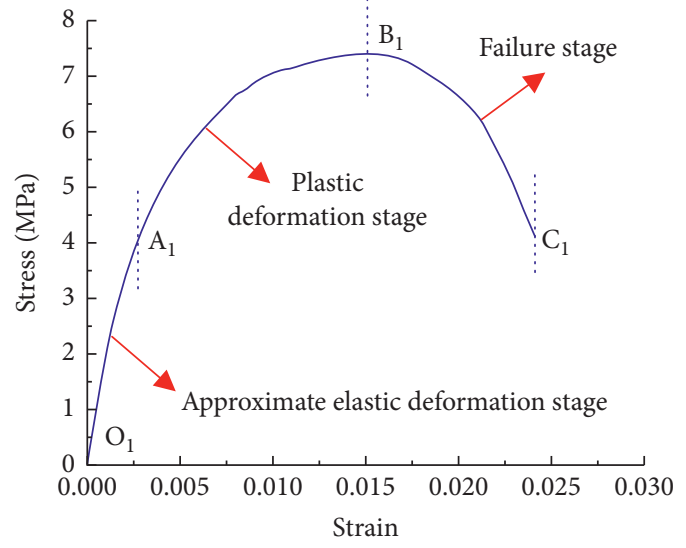

(b)

FIgURE 5: Different stages of typical stress-strain curve. (a) Static compressive test. (b) Dynamic compressive test.

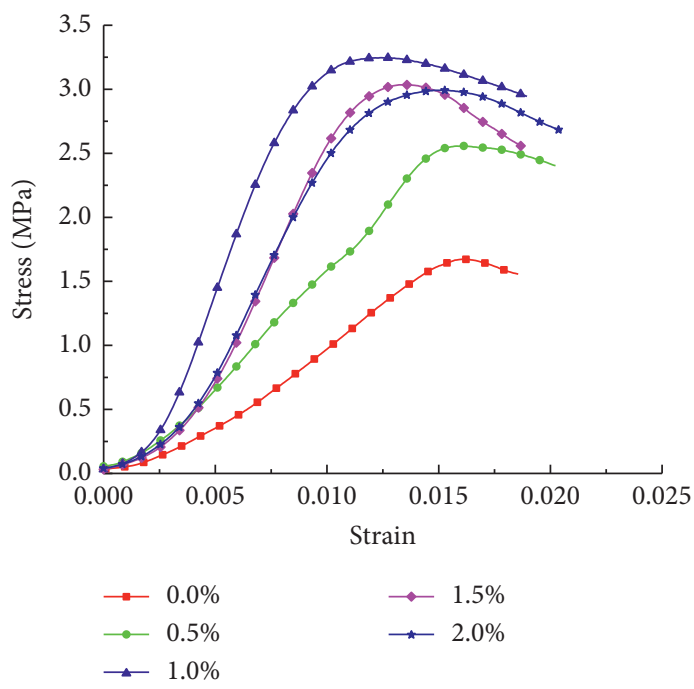

(a)

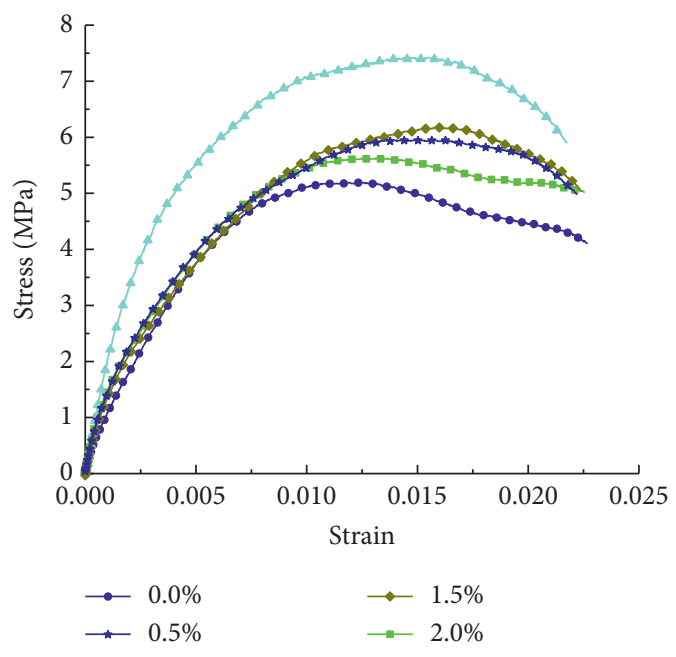

(b)

FIGURE 6: Stress-strain curves with different fiber contents. (a) Static compressive test. (b) Dynamic compressive test.

3.2. Static and Dynamic Compressive Strengths. The effect of basalt fiber content on static and dynamic compressive strength of cement clay could be seen in Figure 8. The compressive strengths of unreinforced cement clay under static and dynamic load tests were $1.95 \mathrm{MPa}$ and $4.1 \mathrm{MPa}$, respectively. The static compressive strength of fiber reinforced specimen with various contents $(0.5 \%, 1 \%, 1.5 \%$, and $2 \%$ ) were $2.6 \mathrm{MPa}, 3.24 \mathrm{MPa}, 3.1 \mathrm{MPa}$, and $3.04 \mathrm{MPa}$, respectively, while the dynamic compressive strength was 5.25 MPa, 7.16 MPa, 6.29 MPa, and 5.79 MPa, respectively. A reasonable explanation for the increase of compressive strength was probably due to the increase of bonding strength and friction between basalt fiber and cement clay matrix [7].

3.3. Static and Dynamic Tensile Strengths. Figure 9 showed the effect of fiber content on static and dynamic tensile strength. The static and dynamic tensile strengths of unreinforced cement soil were $0.32 \mathrm{MPa}$ and $0.42 \mathrm{MPa}$, respectively. Compared with the unreinforced specimen, the tensile strength of specimens with fiber content $1 \%$ was $0.62 \mathrm{MPa}$ and $0.83 \mathrm{MPa}$, respectively, with an increment of $93.75 \%$ and $97.62 \%$, respectively. The improvement of tensile strength which was attributed to the fibers could share some tensile stress because of the movement restraint of fiber in soil matrix [29].

According to the test results, both the strength and $E_{50}$ under dynamic loading were higher than that under static loading. A reasonable explanation for this phenomenon could be obtained as follows: from the perspective of energy, the failure of materials was accompanied by the initiation, development, accumulation, and penetration of internal cracks. In addition, the formation process of microcracks need more energy than the expansion process; therefore, under the dynamic impact condition, the specimen did not had enough time to accumulate energy, and the internal 


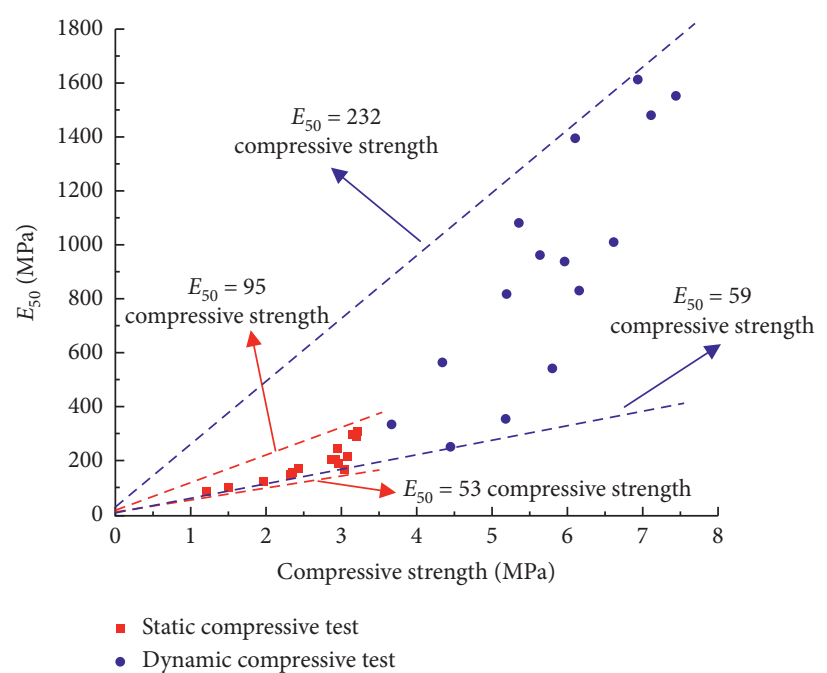

Figure 7: Relationship between $E_{50}$ and peak stress.

microcrack propagation postponed the increase of load. The absorbed energy could not be released by microcrack development, which could accumulate inside the specimen, resulting in the increment of strength $[30,31]$.

3.4. NMR Tests. Cement soil, as a typical porous material, contained numerous irregular and multiscale internal pores, which had a significant influence on its macromechanical properties. Hence, it was necessary to research the internal pore characteristics of cement soil. Compared with other microscopic tests, such as SEM and Mercury intrusion test, NMR had the advantages of fast, nondestructive, intuitive observation, and display, so this method was adapted in this work.

During the test, put specimen into the main magnetic field and then applied a certain frequency radio frequency pulse. The spin hydrogen nucleus of specimen will absorb electromagnetic waves of a certain frequency and transition from low energy state to high energy state, and the magnetization vector will deviate from the equilibrium state. When the radio frequency pulse was stopped, the hydrogen nucleus emitted a current signal at a specific frequency to release the absorbed energy; it could return from an unbalanced state to an equilibrium state. This was the relaxation process, and the required time was relaxation time. The energy release rate and strength changed with the pore structure and fluid property of materials; hence, it could indirectly reflect the characteristics of internal pore structures of geotechnical materials.

Base on the principal of NMR, the total transverse relaxation rate $\left(1 / T_{2}\right)$ [32] could be expressed as follows:

$$
\frac{1}{T_{2}}=\frac{1}{T_{2 \mathrm{~B}}}+\rho_{2}\left(\frac{S}{V}\right)+\frac{D\left(\gamma G T_{\mathrm{E}}\right)^{2}}{12},
$$

where $T_{2 \mathrm{~B}}$ was the volume relaxation time of fluid, (ms); $\rho_{2}$ was surface relativity (um/ms), and $S / V$ was the surface-tovolume ratio $\left(\mu \mathrm{m}^{-1}\right)$ of the pore; and $D, G, T_{\mathrm{E}}$, and $\gamma$ were the diffusion coefficient $(\mu \mathrm{m} / \mathrm{ms})$, magnetic field gradient
$(\mathrm{Gs} / \mathrm{cm})$, echo spacing (ms), and magnetogyric ratio $\left(\mathrm{T}^{-1} \cdot \mathrm{ms}^{-1}\right)$, respectively.

There was only one kind of fluid, and the volume relaxation was much slower than the area relaxation; hence, the $1 / T_{2 \mathrm{~B}}$ could be ignored. When the magnetic field was uniform and the $T_{\mathrm{E}}$ was small, the diffusion relaxation could also be ignored [33]; therefore, equation (2) could be simplified as

$$
\frac{1}{T_{2}}=\rho_{2}\left(\frac{S}{V}\right)
$$

It could be seen from equation (3) that the relaxation rate depended on the surface area-to-volume ratio of the pore [34]. Hence, the $T_{2}$ distribution could reflect the information of pore size and was proportional to the pore diameter; moreover, the amplitude reflected the number of pores. Hence, the change of the internal pore structure could be seen by the various in $T_{2}$ distribution.

Figure 10 illustrated the $T_{2}$ spectrum distribution changing curve of the specimen with different basalt fiber contents. The variation characteristics of the $T_{2}$ spectrum with different basalt fiber contents were almost identical. It was reflected that the distribution of the internal pores was roughly the same. The $T_{2}$ spectrum of the specimen with different fiber contents was composed of two spectral peaks, where the first one was corresponding to a small pore, while the second one was corresponding to a large pore [35]. Moreover, the second spectrum peak was much smaller than the first one, which indicated that the internal pore size had good continuity. As illustrated in Figure 11, the small pores accounted for a large proportion, which reflected the internal pore structure of specimens was compact. According to the NMR test results, the porosity of cement clay could be reduced by mixing the appropriate amount basalt fiber content $(0.5 \% \sim 1 \%)$. However, incorporate larger basalt fiber content $(1.5 \% \sim 2 \%)$ could increase its porosity, which weakened the internal structure of the specimen.

The integrated area of the $T_{2}$ spectrum curve was proportional to the amount of fluid, which existed in the 


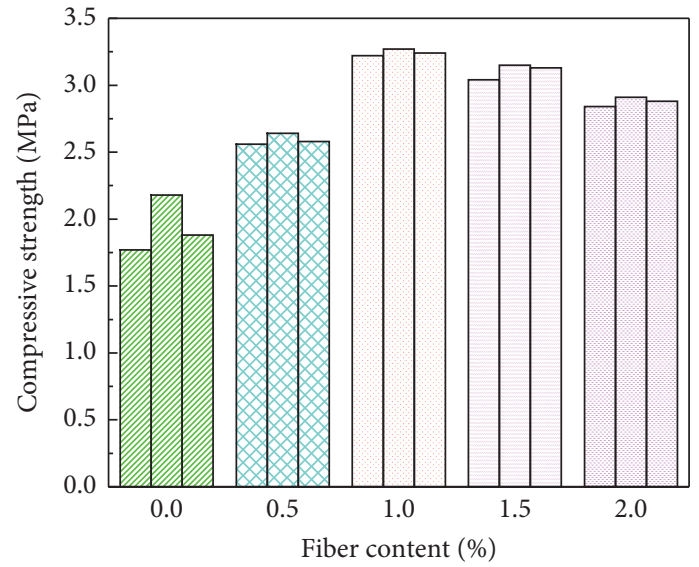

(a)

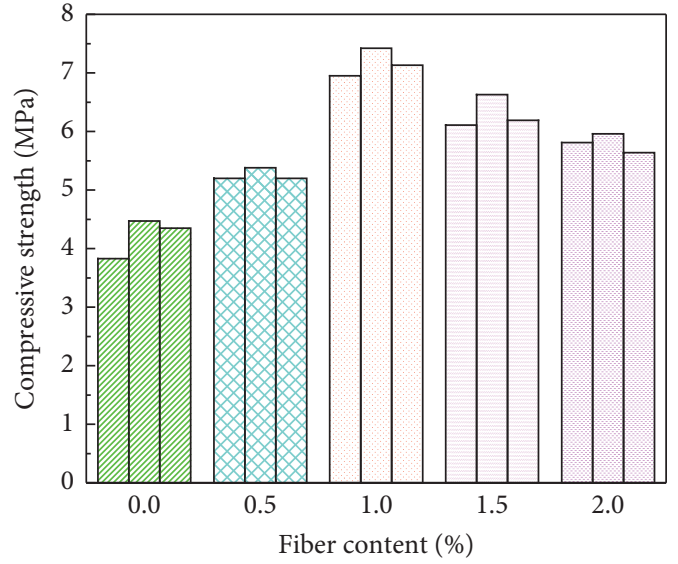

(b)

Figure 8: Effect of fiber content on compressive strength: (a) static compressive strength and (b) dynamic compressive strength.

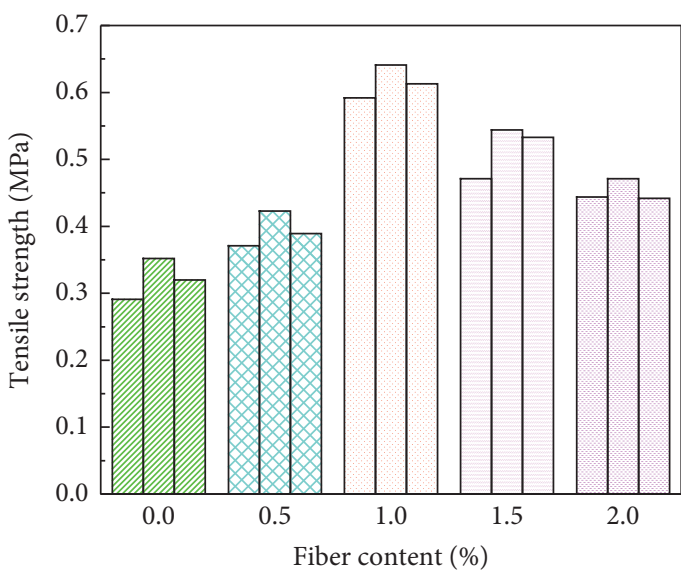

(a)

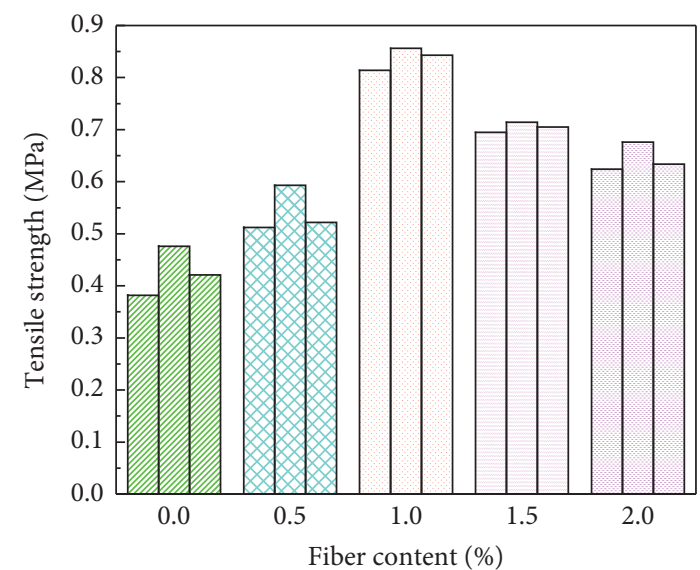

(b)

FIGURE 9: Effect of fiber content on tensile strength: (a) static tensile strength and (b) dynamic tensile strength.

internal pores, and the area was equal to or less than the effective porosity of specimen. The number of corresponding pores was related to the peak area [36]. Hence, the change of the internal pore volume of the specimen could be reflected by the change of the spectrum area. Table 8 showed the spectrum peak area with different fiber contents, and the ratio of the first spectrum area to the total area ranged from $93.3 \%$ to $96.9 \%$.

\section{Reinforcement Mechanism}

4.1. Promote the Hydration Reaction. Cement soil was a typical porous material which contained lot of internal microcracks, holes, and voids, as illustrated in Figure 12. The incorporation of metakaolin could accelerate the hydration reaction of cement and produce more hydration products to fill the internal pores and cracks, which could reduce the porosity and increase the compactness of cement clay, as illustrated in Figure 13. Hence, both the friction force and the effective contact area among fiber, soil particles, and hydration products increased.

4.2. Interaction between Fiber Surface and Cement Clay Interfaces. Basalt fiber, as silicate fiber, had good compatibility with cement-based materials. Figure 14 dominated that a large number of hydration products adhered to the surface of the fiber, which increased the roughness of fiber surface, and cement hydration product crystals had high strength; the stiffness of fibers would be enhanced. Moreover, the hydration products attached to the fiber surface and cement clay matrix were bonding together. In addition, the surface of fiber would be softened by hydration heat of cement [37] and some needle-like 


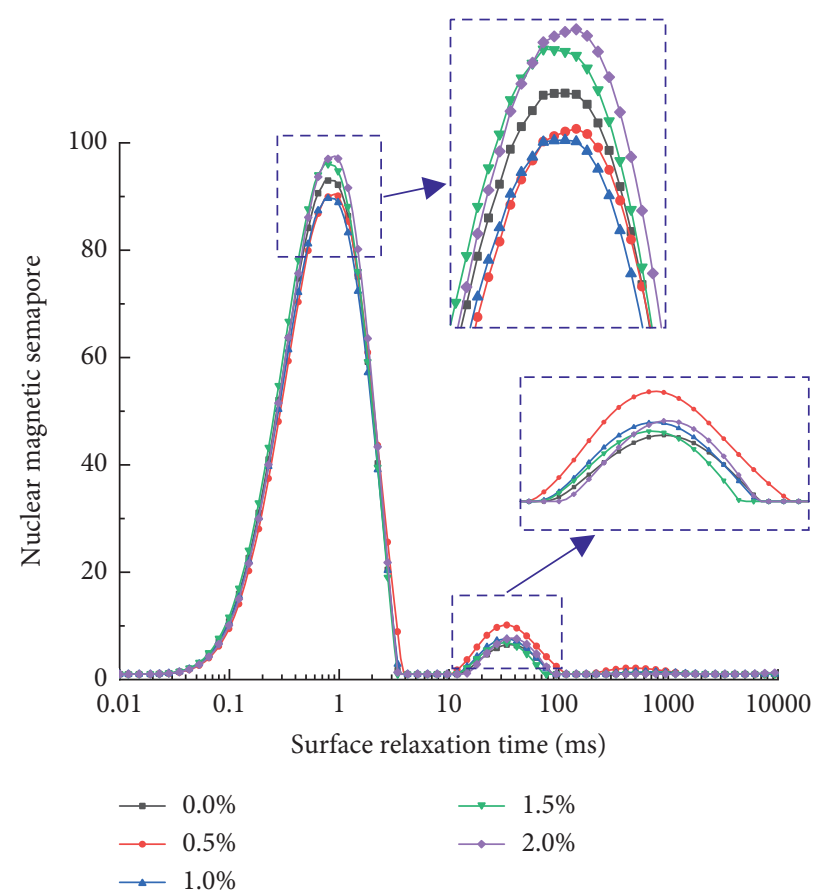

Figure 10: Effect of fiber content on $T_{2}$ variation characteristics.

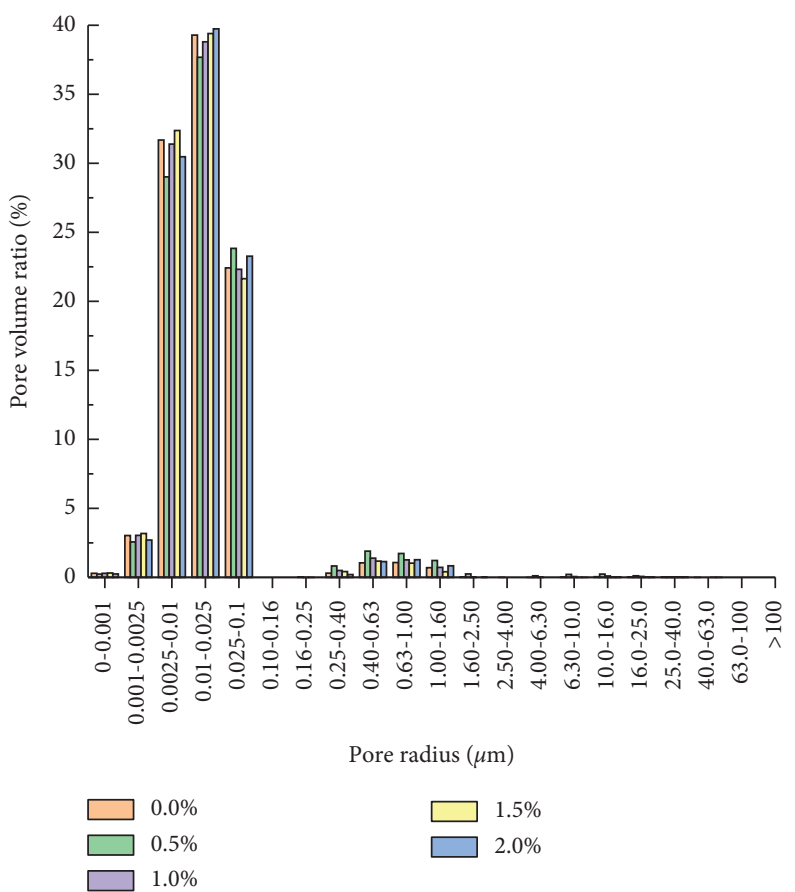

FIgURE 11: Pore radius distribution.

hydration products penetrated the fiber and further increased the bite cooperation force at the interface, as illustrated in Figure 15.

4.3. Anchorage Effect. The cement crystals were bonding together so that they exist on the surface of fiber and cement clay matrix, which could be treated as "anchorage zone," as shown in Figure 16. Under the effect of anchorage, the fibers could effectively inhibit the formation and development of crack propagation. Moreover, the fibers could reduce the stress concentration and increase the fracture toughness of cement soil. As the external load increased, some fibers were broken or pulled out from the cement soil, as illustrated in Figure 17. 
TABle 8: Spectrum area with different fiber contents.

\begin{tabular}{|c|c|c|c|c|c|c|}
\hline Fiber contents (\%) & Spectrum peak number & Peak starting time $(\mathrm{ms})$ & Peak time (ms) & Peak ending time (ms) & Peak area & Ratio (\%) \\
\hline \multirow{2}{*}{0} & 1 & 0.016 & 0.91 & 3.92 & 2807.15 & 93.3 \\
\hline & 2 & 10.35 & 33.70 & 117.59 & 179.56 & 6 \\
\hline \multirow{2}{*}{0.5} & 1 & 0.016 & 0.85 & 3.65 & 2882.59 & 96.7 \\
\hline & 2 & 11.89 & 36.12 & 89.07 & 94.03 & 3.2 \\
\hline \multirow{2}{*}{1} & 1 & 0.016 & 0.85 & 3.65 & 2787.69 & 96.9 \\
\hline & 2 & 11.09 & 33.70 & 89.07 & 113.31 & 3 \\
\hline \multirow{2}{*}{1.5} & 1 & 0.016 & 0.74 & 3.41 & 2975.09 & 96.2 \\
\hline & 2 & 11.09 & 31.44 & 77.53 & 92.94 & 3.1 \\
\hline \multirow{2}{*}{2} & 1 & 0.016 & 0.91 & 3.65 & 2965.68 & 96.5 \\
\hline & 2 & 12.75 & 38.72 & 89.07 & 106.78 & 3.4 \\
\hline
\end{tabular}

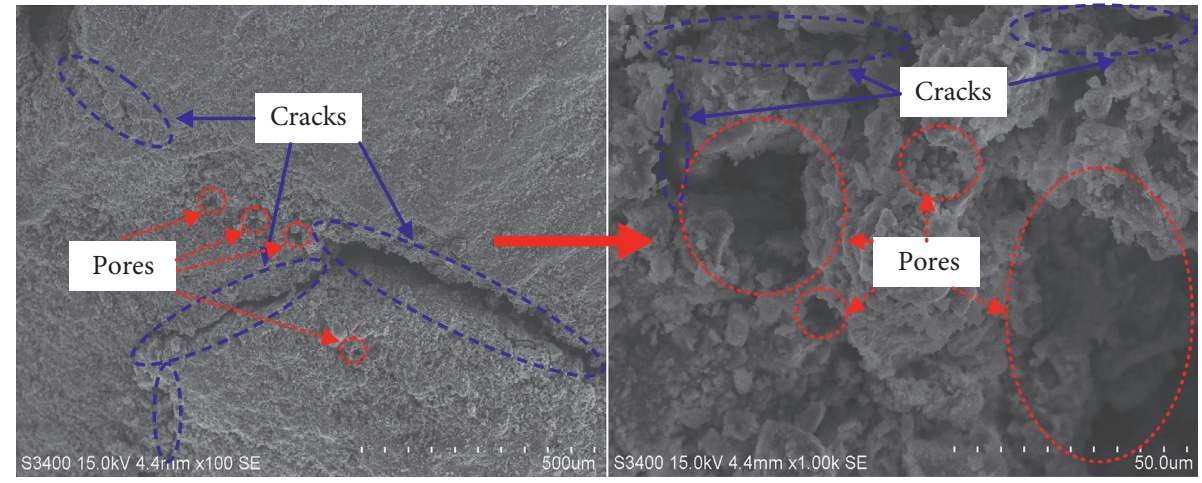

(a)

(b)

FIGURE 12: Micromorphology of cracks and pores of cement clay.

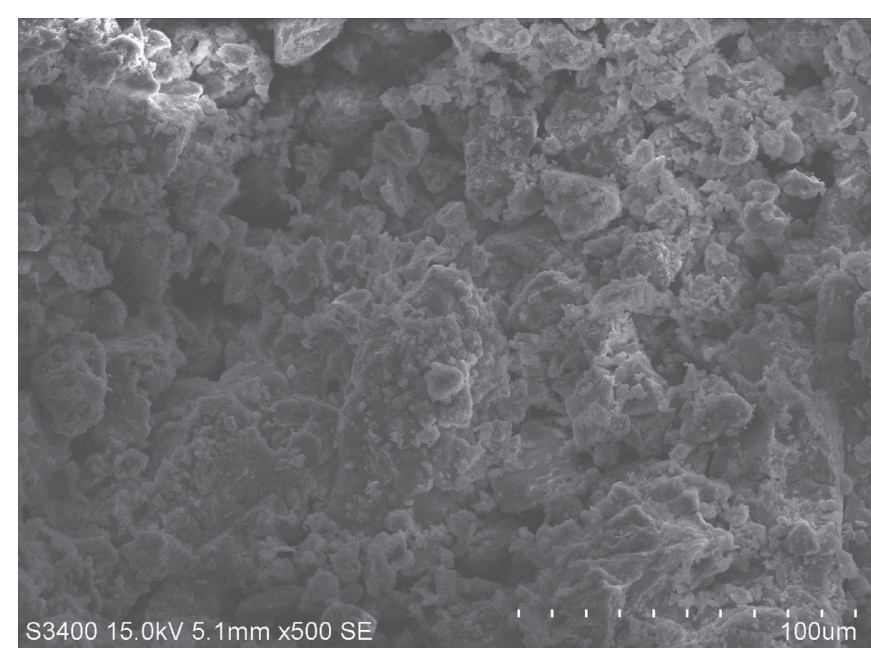

(a)

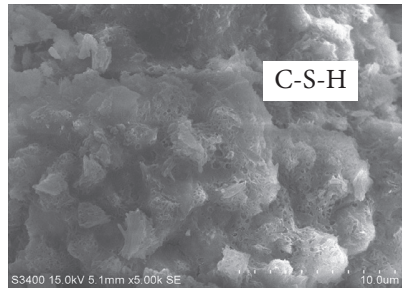

(b)

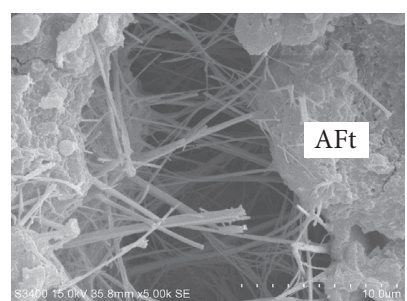

(c)

FIGURE 13: Micromorphology of plain metakaolin-based cement clay.

4.4. Weakening Effect. As heterogeneous composite material, the nonuniformity of cement clay would increase after increasing addition of fibers. Figure 18 revealed that fibers were agglomerated and got tangled up together, which increased the weak points in the mixture. During the loading process, these weak points could cause stress 


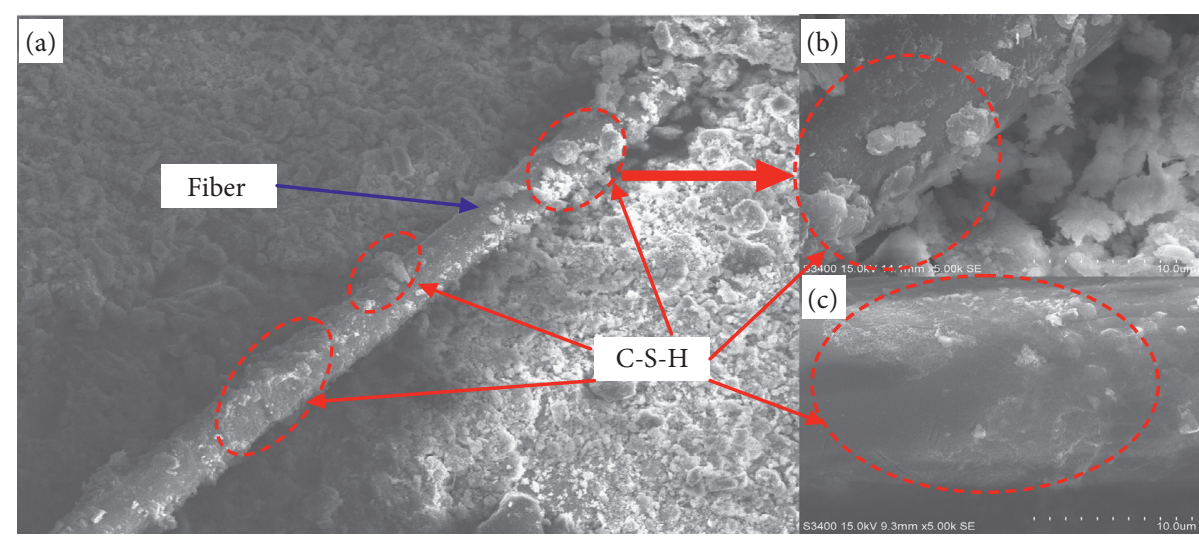

Figure 14: Micromorphology of basalt fiber surface.

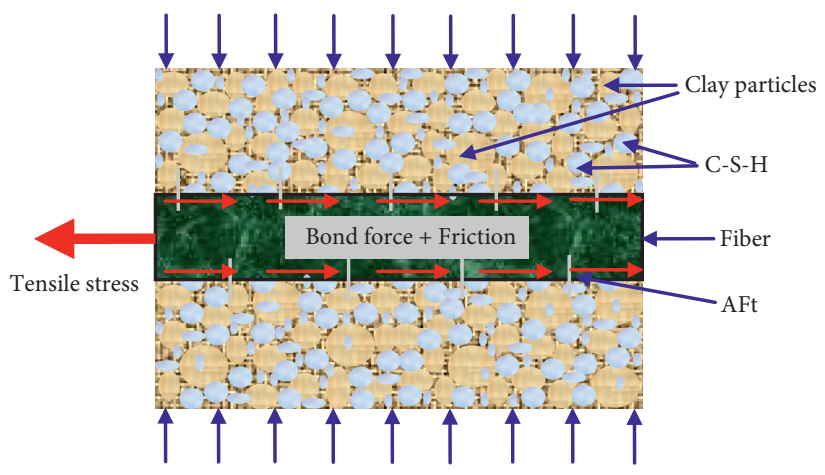

Figure 15: Interface diagram of soil-cement reinforced with fibers.

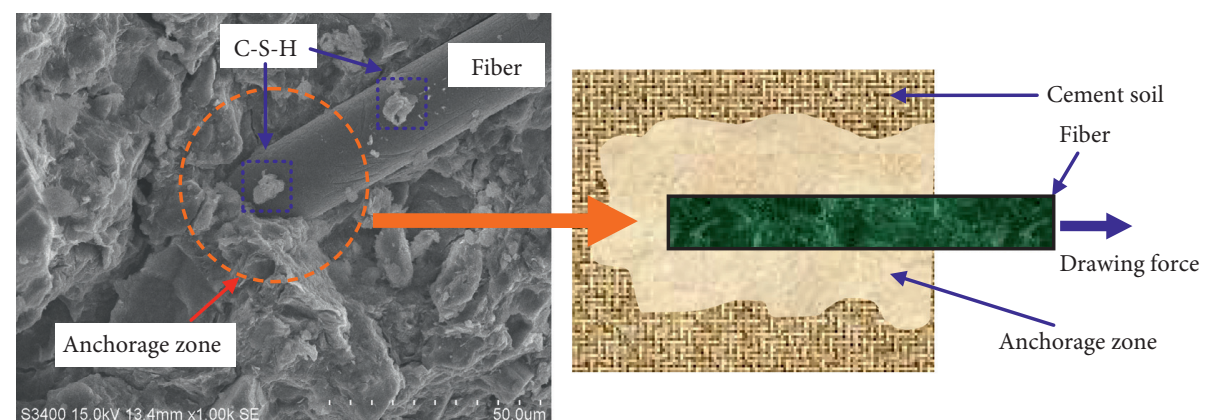

FigURE 16: Schematic diagram of anchoring.

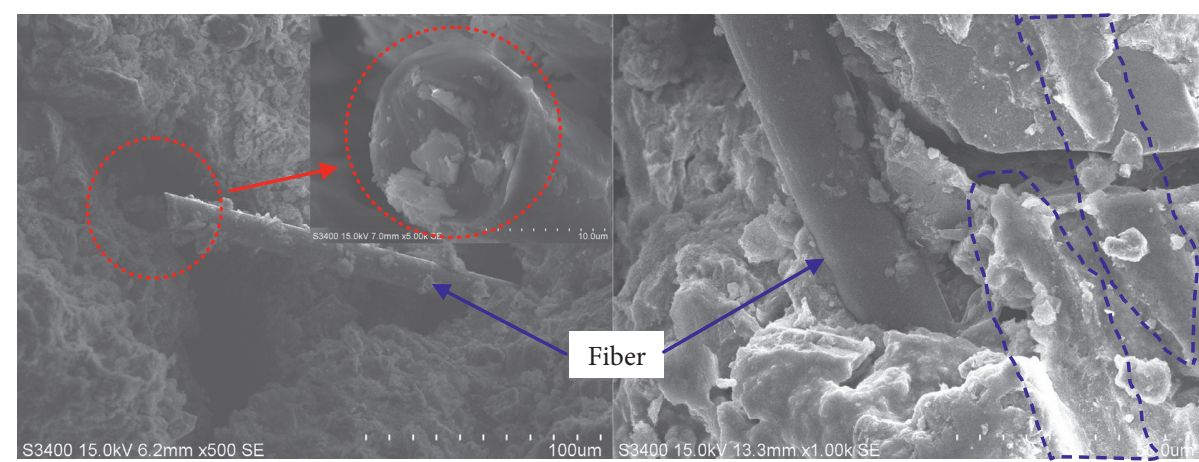

(a)

(b)

Figure 17: Micromorphology of fiber failure. 


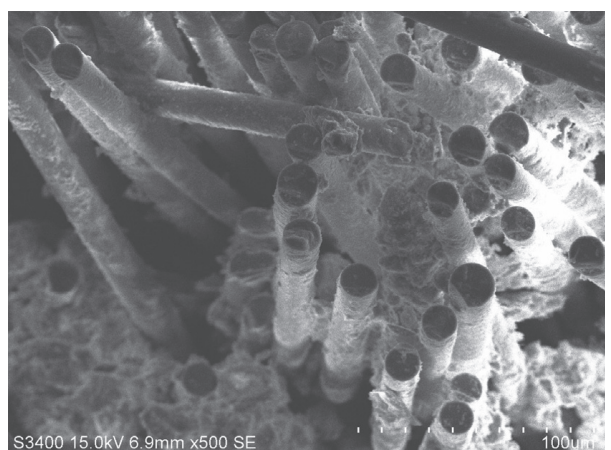

(a)

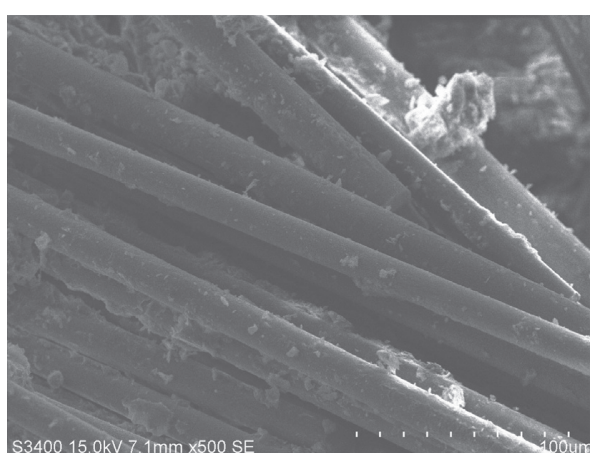

(b)

Figure 18: Micromorphology of fiber aggregation.

concentration [5]. In addition, the agglomeration of fibers reduced the effective area between the fiber and cement clay mixture, and the bond force and the friction between fibers were much smaller than that between fibers and cement clay mixture. Hence, the mechanical properties of cement clay would be weakening when incorporated excessive fiber content.

\section{Conclusions}

(1) The characteristic of stress-strain curves was various under different test conditions. Static compressive test: consolidation stage, linear elastic stage, plastic deformation stage, and failure stage; dynamic compressive test: approximate elastic deformation stage, plastic deformation stage, and failure stage.

(2) The ratio between $E_{50}$ and static compressive strength ranged from 53 to 95 and the ratio between them ranged from 59 to 232 under dynamic impact load, and there showed a positive correlation between deformation modulus and compressive strength. The compressive strength and $E_{50}$ of the specimen under dynamic load were higher compared with that under static load.

(3) Incorporation of appropriate amount of fiber (1\%) could decrease the porosity and enhance the mechanical properties of metakaolin-based cement clay specimens. Compared to the unreinforced specimen, the static compressive strength, split tensile strength, dynamic compressive strength, and dynamic splitting strength were increased by $66.15 \%, 93.75 \%$, $74.63 \%$, and $97.62 \%$, respectively.

\section{Data Availability}

The datasets generated and analyzed during the current study are available from the corresponding author on reasonable request.

\section{Conflicts of Interest}

The authors declare that there are no conflicts of interest regarding the publication of this paper.

\section{Acknowledgments}

This paper was funded by the National Natural Science Foundation of China (no. 50874003), Anhui Provincial Natural Science Foundation (no. 1908085QE212), China Postdoctoral Science Foundation (no. 2019M652162), and Doctoral Fund Project of Anhui University of Science \& Technology (no. 11695). Thanks to the Engineering Research Center of Underground Mine Construction, Ministry of Education and Anhui University of Science \& Technology, for providing the experiment conditions.

\section{References}

[1] M. Ding, F. Zhasng, X. Ling, and B. Lin, "Effects of freezethaw cycles on mechanical properties of polypropylene fiber and cement stabilized clay," Cold Regions Science and Technology, vol. 154, pp. 155-165, 2018.

[2] M. Bekhiti, H. Trouzine, and M. Rabehi, "Influence of waste tire rubber fibers on swelling behavior, unconfined compressive strength and ductility of cement stabilized bentonite clay soil," Construction and Building Materials, vol. 208, pp. 304-313, 2019.

[3] K. Q. Tran, T. Satomi, and H. Takahashi, "Tensile behaviors of natural fiber and cement reinforced soil subject to direct tensile test," Journal of Building Engineering, vol. 24, Article ID 100748, 2019.

[4] X. Chen, X. Shi, J. Zhou, Q. Chen, E. Li, and X. Du, "Compressive behavior and microstructural properties of tailings polypropylene fibre-reinforced cemented paste backfill," Construction and Building Materials, vol. 190, pp. 211-221, 2018.

[5] P. Sukontasukku and P. Jamsawang, "Use of steel and polypropylene fibers to improve flexural performance of deep soil-cement column," Construction and Building Materials, vol. 29, pp. 201-205, 2012.

[6] L. Wei, S. X. Chai, H. Y. Zhang, and Q. Shi, "Mechanical properties of soil reinforced with both lime and four kinds of fiber," Construction and Building Materials, vol. 172, pp. 300-308, 2018.

[7] K. Q. Tran, T. Satomi, and H. Takahashi, "Improvement of mechanical behavior of cemented soil reinforced with waste cornsilk fibers," Construction and Building Materials, vol. 178, pp. 204-210, 2018.

[8] E. Sassoni, S. Manzi, A. Motori, M. Montecchi, and M. Canti, "Novel sustainable hemp-based composites for application in the building industry: Physical, thermal and mechanical 
characterization," Energy and Buildings, vol. 77, pp. 219-226, 2014.

[9] X. Sun, Z. Gao, P. Cao, and C. Zhou, "Mechanical properties tests and multiscale numerical simulations for basalt fiber reinforced concrete," Construction and Building Materials, vol. 202, pp. 58-72, 2019.

[10] F. Chen, "Experiment research on tensile strength of basalt fiber cement-soil," Journal of Shenzhen University Science and Engineering, vol. 33, no. 2, pp. 188-193, 2016.

[11] A. Boz and A. Sezer, "Influence of fiber type and content on freeze-thaw resistance of fiber reinforced lime stabilized clay," Cold Regions Science and Technology, vol. 151, pp. 359-366, 2018.

[12] S. Samal, N. Phan Thanh, I. Petríková, B. Marvalová, K. A. M. Vallons, and S. V. Lomov, "Correlation of microstructure and mechanical properties of various fabric reinforced geo-polymer composites after exposure to elevated temperature," Ceramics International, vol. 41, no. 9, pp. 12115-12129, 2015.

[13] G. Long, L. Li, W. Li et al., "Enhanced mechanical properties and durability of coal gangue reinforced cement-soil mixture for foundation treatments," Journal of Cleaner Production, vol. 231, pp. 468-482, 2019.

[14] Z. Wu, Y. Deng, S. Liu, Q. Liu, Y. Chen, and F. Zha, "Strength and micro-structure evolution of compacted soils modified by admixtures of cement and metakaolin," Applied Clay Science, vol. 127-128, pp. 44-51, 2016.

[15] R. R. Zhang and D. D. Ma, "Effects of curing time on the mechanical property and micro-structure characteristics of metakaolin based geopolymer cement-stabilized silty clay," Advance in Materials Science and Engineering, vol. 2020, Article ID 9605941, 9 pages, 2020.

[16] Y. F. Deng, Z. L. Wu, S. Y. Liu et al., "Influence of geopolymer on strength of cement-stabilized soils and its mechanism," Chinese Journal of Geotechnical Engineering, vol. 38, no. 3, pp. 446-453, 2016.

[17] Z. L. Wu, X. Y. Zhu, Y. F. Deng, H. S. Liu, and P. S. Zha, "Behavior and micro-mechanism of cement-based modified compaction soil composed of steel slag and metakaolin," China Journal of Highway Transport, vol. 30, no. 9, pp. 18-26, 2017.

[18] Q. Y. Ma and C. H. Gao, "Energy absorption and fractal characteristics of basalt fiber-reinforced cement soil under impact loads," Rock and Soil Mechanics, vol. 39, pp. 39213958, 2018.

[19] R. L. Santoni and S. L. Webster, "Airfields and roads construction using fiber stabilization of sands," Journal of Transportation Engineering, vol. 2, no. 127, pp. 96-104, 2001.

[20] Q. Y. Ma and C. H. Gao, "Effects of basalt fiber on the dynamic mechanical properties of cement soil in SHPB test," Journal of Materials in Civil Engineering, vol. 30, no. 8, Article ID 04018185, 2018.

[21] People's Republic of China Industry Standard, Technical Code for Ground Treatment of Buildings (JGJ 79-2012), China Architecture \& Building Press, Beijing, China, 2012, in Chinese.

[22] People's Republic of China National Standards, Standard for Geotechnical Testing Method (G/B 50123-2019), China Planning Press, Beijing, China, 2019, in Chinese.

[23] D. D. Ma, Q. Y. Ma, Z. M. Yao, and K. Huang, "Static and dynamic coupling mechanical properties and constitutive model of artificial silty clay under triaxial compressive," Cold Regions Science and Technology, vol. 167, Article ID 102858, 2019.
[24] D. Ai, Y. Zhao, Q. Wang, and C. Li, "Experimental and numerical investigation of crack propagation and dynamic properties of rock in SHPB indirect tension test," International Journal of Impact Engineering, vol. 126, pp. 135-146, 2019.

[25] L. B. Fan, D. W. Zhang, and Y. F. Deng, "Experimental study of stress-strain characteristics of cement treated chlorate salt rich clays," Journal of Engineering Geology, vol. 20, no. 4, pp. 621-626, 2012.

[26] Y. J. Du, M. L. Wei, F. Jin, and Z. B. Liu, "Stress-strain relation and strength characteristics of cement treated zinc-contaminated clay," Engineering Geology, vol. 167, no. 17, pp. 45-53, 2013.

[27] L. Wang, X. Li, Y. Cheng, and X. Bai, "Effects of coal-metakaolin on the properties of cemented sandy soil and its mechanisms," Construction and Building Materials, vol. 166, pp. 592-600, 2018.

[28] Y. Yilmaz and V. Ozaydin, "Compaction and shear strength characteristics of colemanite ore waste modified active belite cement stabilized high plasticity soils," Engineering Geology, vol. 155, pp. 45-53, 2013.

[29] J. Li, C. Tang, D. Wang, X. Pei, and B. Shi, "Effect of discrete fibre reinforcement on soil tensile strength," Journal of Rock Mechanics and Geotechnical Engineering, vol. 6, no. 2, pp. 133-137, 2014.

[30] W. G. Liang, S. G. Xu, J. Mo, D. Wu, and C. D. Zhang, "Test study of strain rate effects on mechanical performances of salt rock," Chinese Journal of Rock Mechanics and Engineering, vol. 29, no. 1, pp. 43-50, 2010.

[31] H. Zhang, B. Wang, A. Xie, and Y. Qi, "Experimental study on dynamic mechanical properties and constitutive model of basalt fiber reinforced concrete," Construction and Building Materials, vol. 152, pp. 154-167, 2017.

[32] M. Tan, L. Fan, K. Mao, J. Li, and C. Wu, "Influential factors analysis and porosity correction method of nuclear magnetic resonance measurement in igneous rocks," Journal of Applied Geophysics, vol. 161, pp. 153-166, 2019.

[33] C. M. Zhang, Z. B. Chen, Z. S. Zhang, J. Li, H. S. Ling, and B. D. Sun, "Fractal characteristics of reservoir rock pore structure based on NMR T2 distribution," Journal of Oil and Gas Technology, vol. 29, no. 4, pp. 80-86, 2007, in Chinese.

[34] C. D. Zhang and Y. L. Pan, "Some views on petrophysical interpretation of SNMR data," Chinese Journal of Engineering Geophysics, vol. 3, no. 1, pp. 1-8, 2006, in Chinese.

[35] K. Zhou, T. Liu, and Z. Hu, "Exploration of damage evolution in marble due to lateral unloading using nuclear magnetic resonance," Engineering Geology, vol. 244, pp. 75-85, 2018.

[36] X. B. Li, L. Wong, X. F. Xie, and Q. H. Wu, "Study on the degradation of hard rock with a pre-existing opening under static and dynamic loadings using nuclear magnetic resonance technique," Chinese Journal of Rock Mechanics and Engineering, vol. 34, no. 10, pp. 1985-1993, 2015.

[37] A. Tagnit-Hamou, Y. Vanhove, and N. Petrov, "Microstructural analysis of the bond mechanism between polyolefin fibers and cement pastes," Cement and Concrete Research, vol. 35, no. 2, pp. 364-370, 2005. 